\title{
A ESCOLA SEBASTIÃO TOLEDO SANTOS ENTRE O ENSINO E A PRÁTICA DOCENTE: O AUDIOVISUAL COMO RECURSO DIDÁTICO NAS AULAS DE HISTÓRIA
}

\author{
Rodrigo Margotti ${ }^{1}$, Luana Josephino de Melo ${ }^{1}$, Jucilene de Souza Plácido Francisco ${ }^{1}$
}

\begin{abstract}
RESUMO
O presente artigo vai discutir as experiências com a docência, de acadêmicos (as) do curso de História da Universidade do Extremo Sul Catarinense - UNESC, através do Programa Institucional de Bolsa de Iniciação à Docência (PIBID) com a turma do Magistério VI da Escola Engenheiro Sebastião Toledo dos Santos em Criciúma / SC. Anteriormente a essa questão, propor uma reflexão acerca dos conceitos que nortearam a relação entre o ensino e prática da futura docência. Além disso, compartilhar as experiências obtidas em sala de aula com o projeto "Cinema na Escola", que utilizou o audiovisual como recurso didático. Perante isso, foi realizada uma oficina de documentação para suporte da construção do curtametragem, para enfim iniciar a escrita do roteiro, edição e finalização do curta-metragem, contando a participação do Colegião no movimento estudantil e dos professores perante essa práxis social.

Palavras-chave: Audiovisual; Documentação; Memória; Movimento Estudantil.
\end{abstract}

\begin{abstract}
This article will discuss the experiences with teaching, academic (the) course History of Universidade do Extremo Sul Catarinense - UNESC by the Institutional Program Initiation Grant to Teaching (PIBID) with the class of the Magisterium VI Engineer School Sebastian Toledo dos Santos in Criciúma / SC. Prior to this issue, proposing a reflection on the concepts that guided the relationship between teaching and practice of future teaching. Also, share the experiences in the classroom with the project "Cinema at School", which was used as the audiovisual teaching resource. In view of this, a documentation workshop to support the construction of the short film was made to finally start writing the script, editing and finalization of the short film telling the participation of Colegião in the student movement and teachers before this social praxis.

Keywords: Audiovisual; Documentation; Memory; Student Movement.
\end{abstract}

\footnotetext{
${ }^{1}$ Universidade do Extremo Sul Catarinense - Unesc.
} 


\section{INTRODUÇÃO}

A presente pesquisa está inserida no Programa Institucional de Bolsas e Iniciação a Docência - PIBID órgão vinculado a CAPES - Coordenaria de Aperfeiçoamento de Pessoal de Nível Superior, este de competência federal. É nessa esfera que o subprojeto de História da Universidade do Extremo Sul Catarinense - Unesc se adentra com o objetivo de fortalecer e aprimorar a capacitação bem como a formação dos acadêmicos bolsistas na área, condicionando um profissional engajado com os requisitos indispensáveis para o conhecimento histórico, pois o programa tem a capacidade de estimular e consolidar a práxis docente do mesmo modo que articula o saber entre a teoria e a prática do professor.

É nesse âmbito que o subprojeto de história da Unesc vem por meio do Pibid, buscar incorporar formas de ensino e aprendizagem entre acadêmicos / bolsitas do programa para com as escolas participantes do mesmo. Hoje o subprojeto de história conta com três escolas participantes entre elas a Escola Municipal de Educação Fundamental Hercílio Amante localizada no Bairro Floresta, a Escola de Educação Básica Engenheiro Sebastião Toledo Santos localizada no Bairro Comerciário e a Escola Jorge da Cunha Carneiro, ambas situadas no município de Criciúma - SC. Além das escolas, possui vinte e cinco bolsistas redistribuídos entre as três escolas assim como três supervisores de área e dois coordenadores institucionais envolvidos diretamente com o subprojeto do curso da respectiva universidade.

Diante disso, o subprojeto Pibid de história iniciou suas atividades no primeiro semestre de 2014, ainda timidamente, porém com a coragem de possibilitar aos novos bolsitas uma oportunidade impar para com a prática docente. E desde quando as atividades foram sendo desenvolvidas tais como leituras de textos relacionados às temáticas condizentes com os eixos e propostas da área, leituras de referenciais básicos e complementares, estudos de casos, fichamentos de textos, seminários, desenvolvimento e ações de projetos aplicados nas escolas e socializados em seminários na Universidade como em Simpósios, Congressos e no Evento Institucional do Pibid que ocorreu em 2015 e nesse ano - 2016 no II Congresso Ibero Americano na Unesc, além de participação de bolsistas que apresentaram por meio do Pibid, seus projetos de pesquisas nos Encontros Regionais do Pibid, como o ocorrido em Lages no ano de 2015 e também no mesmo ano foi apresentado no XXVIII Simpósio Nacional de História da ANPUH ocorrido em Florianópolis - SC nos dias 27 - 31 de julho um projeto de pesquisa desenvolvido pelos bolsistas da Escola de Educação Básica Engo . Sebastião Toledo Santos. 
O objetivo do estudo do ano de 2015 girou em torno das questões correlativas a documentação, preservação e salvaguarda dos mesmos e na instrumentalização dos bolsistas a respeito dos registros documentais para a construção e elaboração de um audiovisual que contasse com a participação dos alunos envolvidos das escolas participantes do subprojeto. Para tanto, tomou-se como partido os estudos de referenciais teóricos que subsidiassem e possibilitassem dar base para o conhecimento em torno da temática. Foram pertinentes as leituras oriundas da temática sobre audiovisual na reflexão de Rafael Rosa Hagemeyer no seu livro História \& Audiovisual, especificadamente no capítulo III: A história nos meios audiovisuais: entre a veracidade do registro e o poder evocativo das simulações.

De mais a mais, as ponderações em torno da temática do documento nos fez entender a partir das apreensões do entendimento a partir do teor proposto a ideia que a autora Eni de Mesquita Samara e Ismênia S. Silveira. T. Tupy no livro História \& documento $e$ metodologia de pesquisa no capítulo $O$ trabalho com o documento para assimilarmos e sistematizarmos a proposta do subprojeto que foi sendo desenvolvido durante o ano de 2015 nas escolas participantes. No caso do nosso grupo composto por quatro membros, sendo eles: Clarice Evaristo Vieira, Jucilene de Souza Placido Francisco, Luana Josephino de Melo e Rodrigo Margotti, onde a escola a qual desenvolvemos e construímos juntamente com os alunos o audiovisual foi a Escola Eng ${ }^{\circ}$. Sebastião Toledo Santos tendo como supervisora a professora Marly Salvan.

Visto isso, é compreensível destacarmos outras referências que foram substanciais para a preparação e desenvolvimento bem como a construção do audiovisual. Entre elas podese destacar os estudos de Circe Maria Fernandes Bittencourt no livro Ensino de História: fundamentos e métodos onde possui o assunto Usos didáticos de documentos que discute a importância dos documentos como registros históricos e possíveis usos na educação de história. Além destes estudos, tem-se a relevância da abordagem sobre o conceito de memória as concepções do autor francês Jacques Le Goff, que por sinal é muito difundido na academia do curso de história e que também nos serviu como base e inspiração para discutirmos o conceito de memória como elo de aproximação do passado, ou seja, "a memória, como propriedade de conservar certas informações, remete-nos em primeiro lugar a um conjunto de funções psíquicas, graças as quais o homem pode atualizar impressões ou informações passadas" (LE GOFF, 1992, p. 419). 
Para além das bases teóricas basilares e complementares citadas acima é merecedor situar o livro de Maria da Glória Gohn "Movimentos Sociais e Educação" o qual foi fundante para a elaboração da pertinência da temática do nosso audiovisual intitulada A ESCOLA SEBASTIÃO TOLEDO SANTOS E OS MOVIMENTOS SOCIAIS pois o mesmo aborda a participação dos movimentos sociais nas esferas políticas possibilitando uma demanda nas questões concernentes da sociedade civil. Não sem motivo, Marta de Souza Lima Brodbeck na obra Vivenciando a História - Metodologia de Ensino da História nos aproxima da compreensão em torno da temática no que se refere nas compreensões das diversas práticas no ensino de história como o trabalho com imagens, mapas, a formação de conceitos entre outros. Assim como propostas de atividades práticas, tendo entre elas a forma de como trabalhar com o conceito de tempo. Além disso, a organização do livro foi pensada para que se possa estabelecer uma troca de experiências com outros professores a fim de que os recursos didáticos possam ser repensados e aprendidos no contexto escolar. É pertinente sobrelevar nesta obra as reflexões em torno das práticas no ensino de história atinente ao trabalho com textos e documentos históricos que vão de encontro com a temática expandida durante a elaboração do audiovisual no ano passado do subprojeto de História da Universidade.

Diante do descrito acima, entende-se que para a construção de um audiovisual, ou mais especificadamente de um curta metragem o qual foi realizado com a turma do magistério da escola Eng ${ }^{\circ}$ Sebastião Toledo Santos, foi imprescindível compreender as questões que envolvem os suportes de informações que são os documentos. E para tanto, na elaboração do audiovisual visando à participação dos alunos na própria construção do mesmo, possibilita ao professor práticas pedagógicas e novas formas de construir o conhecimento histórico, visto que:

[...] o estudo e a análise de fontes históricas pode ser um ponto de partida do que entendemos como "o fazer histórico" na sala de aula, ajudando o aluno a desenvolver o espírito crítico, a interpretação e o significado de fonte histórica assim como possibilita ao aluno a percepção sobre o ofício do historiador e sobre o trabalho de escrever a História a partir das fontes (BRODBECK, 2012, p. 35).

Nesse viés, ao trabalhar com as fontes históricas não só da própria escola, mas das fontes que serviram de base para a construção do audiovisual tais como as do Acervo Público Municipal de Criciúma nos condicionaram e nos oportunizaram como bolsistas e futuros historiadores professores com a prática do ofício e mais, preparar e instrumentalizar os alunos a investigar as fontes e se verem partícipes do conhecimento histórico, isto é, a partir do 
momento em que os mesmos se veem atuantes na construção do audiovisual, os aproximam do processo de ensino aprendizagem de forma dinâmica e crítica, oportunizando uma identificação com o ensino.

Sendo assim, ao deparar com os registros e fontes históricas na construção do audiovisual, tem-se o cuidado de que as próprias fontes documentais são fragmentos do nosso passado e que os mesmos não contém e / ou abarcam toda a tessitura histórica de determinado fato - acontecimento da história. E para isso, é relevante que o historiador analise o documento como uma possibilidade construtiva, específico em si e que tal fonte histórica, no caso os documentos, sejam estudados na sua dimensão tanto material quanto simbólica. ${ }^{2}$

Quando nos reportamos a tal assunto, podemos analisar que para a construção de um audiovisual, para além dos materiais necessários na sua elaboração, o ofício do historiador perpassa um caminho de seleção e isso coloca a visão de determinado grupo e / ou segmento social perante a temática a qual se quer analisar e para o público externo o qual identificará aquilo que o (s) diretor (res) elaborou (ram) sobre o mesmo. E é isso o qual muitas vezes o professor de história esquece ou não problematiza o que está por trás, isto é, aquilo que o audiovisual não mostrou. Em contrapartida, evidenciar elementos, ou melhor, historicizar a temática é elementar para analisar não somente aquilo que é passado na tela, mas sim buscar outros olhares e ampliar a visão perante o audiovisual exposto.

Vale refutar que para a percepção do documento aqui analisado, é notório evidenciarmos a apreensão de história a qual nos faz entender que o conceito de história é classificada e atribuída conforme o passar do tempo e varia de sociedade para sociedade. Muitos são os historiadores e suas respectivas escolas preocupadas com o saber historiográfico que procuram definir o que é História. Sobre tal assunto, pode-se afirmar, com base no que diz Silva e Silva (2012, p. 183), que:

O conceito de historicidade indica o próprio pertencer de cada indivíduo a seu tempo, e existe para toda a espécie humana. Logo, não há sociedades sem história e a própria história tem uma História, visto que o ato de contar, descrever e analisar o passado depende da sociedade e do período de cada contador. Tudo na História deve ser pensado em seu tempo, isto é, a historicidade.

Nesse sentido, vamos ao encontro do pensamento do historiador Jacques Le Goff, pertencente a uma corrente historiográfica da Nova História, isto é, corrente historiográfica surgida a partir das novas concepções da História na Escola dos Annales na França. Para Le

\footnotetext{
${ }^{2}$ Entende-se neste artigo como entendimento do documento na sua dimensão material os aspectos reproduzidos da natureza, os tamanhos e técnicas empregadas; já o simbólico refere-se aos discursos, linguagens e sentidos atribuídos aos documentos.
} 
Goff, o próprio termo de historicidade deve ser questionado, visto que em determinado período os homens distribuem interesses e visões particulares que são únicas e que fazem parte da mesma conjuntura sobre a afirmação do caráter histórico. Le Goff ainda nos faz pensar que conceitualmente a história transcorre com o passar do tempo e que a mesma é enigmática e inconstante o que para isso é preciso estabelecer uma interpretação da relação entre o passado e o presente, o qual Le Goff entende que "a história vivida das sociedades humanas e o esforço científico para descrevê-la e interpretá-la são os dois polos entre os quais se resume o próprio conceito de história" (LE GOFF, 2003).

Perante isso, e no conjunto da construção do nosso audiovisual, é relevante abordar essa dimensão sobre a história e o documento, pois ambos são elementos bases não só para o enredo e construção do audiovisual, mas que denotam um sentido de estabelecer relações sociais tanto da própria história quanto do documento, pois este revela não só apenas aquilo que está escrito, mas criam conexões e estabelecem a investigação do fato histórico. Sendo assim, é proveitoso perceber que no pensamento de Le Goff acerca dos aspectos que envolvem a memória, cujo sentido nos faz entender uma ligação com o documento e a história, pois os mesmos remetem a uma peculiaridade de armazenar certas informações, logo a teoria de Le Goff revela-se um tanto quanto indispensável para o entendimento da memória e que foi fundamental para as discussões teóricas na construção do audiovisual, a saber que Henri Atlan (apud LE GOFF, 2003, p. 421):

A utilização de uma linguagem falada, depois escrita, é de fato uma extensão fundamental das possibilidades de armazenamento da nossa memória que, graças a isso, pode sair dos limites físicos do nosso corpo para se interpor quer nos outros, quer nas bibliotecas. Isto significa que, antes de ser falada ou escrita, existe uma certa linguagem sob a forma de armazenamento de informações na nossa memória.

Além disso, é mensurável destacar a contribuição dos usos didáticos que os documentos possuem em relação aos saberes em sala de aula. Com isso, na construção do audiovisual foram relevantes os estudos de Circe Maria Fernandes Bittencourt e Eni De Mesquita Samara e Ismênia S. Silveira Tupy, ambas já citadas no início do artigo. Bittencourt, ao colocar o documento como fonte de pesquisa e possibilidade de trabalhar o documento em sala de aula, nos faz compreender que quando o professor irá introduzir o pensamento histórico nos alunos ainda comete-se um equívoco se os mesmos pretendem torná-los pequenos historiadores, pois há uma forma de se tratar o documento da perspectiva da profissão de historiador em relação à didática da história. 
Diante do exposto e para que o documento tenha uma possibilidade de uso didático nas salas de aula de história é pertinente e sugestivo que o professor obtenha objetivos e critérios claros na seleção dos documentos nas aulas de história. Desta forma, o documento pode vir a contribuir num reforço de uma ideia, como fonte de informação e também numa situação problema ao iniciar determinado tema (BITTENCOURT, 2004). O que nos faz entender, que o documento contribui de forma a aprimorar o conhecimento sobre determinada temática em que o professor esteja trabalhando em sala de aula. No caso específico do nosso audiovisual, ao trabalharmos as questões inerentes aos cuidados como preservação e salvaguarda do documento aplicados em modos de oficinas tanto para os bolsistas do Pibid quanto para a turma que desenvolvemos o projeto da escola, foram significativos para o saber sobre os usos que o documento pode vir a coadjuvar na educação sobre o entendimento histórico, no caso, sobre a importância do documento como fonte de informação e construção do audiovisual.

Por este prisma, Eni De Mesquita Samara e Ismênia S. Silveira Tupy ao tratar o documento como objeto de trabalho para o historiador, discutem que atualmente com a democratização do conhecimento, não fica somente no registro escrito, ou seja, seus campos de pesquisa estão em: jornais, internet, livros, noticiários de rádio e televisão, além claro, dos arquivos nacionais, estaduais e municipais. E para tanto, ao darmos ação na construção do audiovisual no ano passado, juntamente com a participação e os olhares dos alunos da escola, objetivamos pesquisas em jornais no Arquivo Público Municipal de Criciúma além dos documentos da escola Eng ${ }^{\circ}$ Sebastião Toledo Santos, o que dessa forma propiciou novos campos e composições na estrutura e consequentemente na construção do audiovisual, o que vai de acordo com o que Samara e Tupy analisam (SAMARA; TUPY, 2010). Sendo assim, é de fundamental importância lidar com as fontes documentais, já que o campo da pesquisa histórica, atualmente, não se restringe apenas a documentos escritos, já que o processo de pesquisa ampliou o modo de registros das diversas formas em lidar com o documento.

Em consonância ao pensamento supracitado, revela-se como necessário a discussão que Rafael Hagemeyer nos traz a respeito de como abordar de forma a perceber a veracidade do registro e a forma como o mesmo possui como um poder que evoca simulações a partir dos recursos audiovisuais e os conteúdos históricos, ou como o próprio autor aborda, as chamadas "reconstituições de época". O que nos faz perceber, e criando uma associação de como abordar determinados assuntos com conteúdo histórico nas salas de aula, no que tange as 
questões audiovisuais é que atualmente, são perceptíveis os usos que os professores de história fazem em relação aos recursos fílmicos, pois entrelaçam o conteúdo e tornam a aula mais dinâmica, porém ao menos se espera que o filme não fique apenas como entretenimento e passatempo dos alunos, já que segundo Hagemeyer (2012, p.112) verifica-se o seguinte argumento:

é sintomática hoje que nas listas de filmes disponíveis na internet voltados para o ensino de história haja a presença maciça de obras de ficção consagradas no cinema e na televisão, as chamadas "reconstituições de época", cuja trama é ambientada em algum momento do passado. As razões desse tipo de preferência são muitas: são filmes mais fáceis de encontrar; atraem a atenção dos alunos, uma vez que fazem uso da narrativa clássica, provocando a identificação através de uma linguagem à qual os alunos já estão acostumados.

Em contrapartida, buscou-se por meio da compreensão e dos apontamentos com que Hagemeyer alude suprir essa visão em torno dos usos audiovisuais como meramente um entretenimento nas aulas de história. No qual foi possível perante a aplicação do projeto do Pibid e com a construção do curta metragem, no entanto, anteriormente problematizar o audiovisual com os alunos e possibilitar e sistematizá-los além do que está exposto no filme, ou seja, criar conexões reflexivas para além da intencionalidade do diretor, o que está por trás, o que o filme não aborda, para assim oportunizar uma tomada de consciência a respeito das ideologias vinculadas cinematograficamente e que muitas vezes são assimiladas como natural. Com efeito, e desta forma, os filmes tidos como "entretenimento" e que é pertinente a sua contestação no ambiente escolar, especificadamente nas aulas de história, analisar para que esses filmes não possam fazer de refém as instituições de ensino reféns "da linguagem audiovisual hegemônica nos meios comerciais" (HAGEMEYER, 2012, p. 112).

Por conseguinte e no que condiz na elaboração e construção do nosso audiovisual, cuja temática foi mencionada anteriormente mas que vale a pena frisar, A ESCOLA SEBASTIÃO TOLEDO SANTOS E OS MOVIMENTOS SOCIAIS, nos baseamos nos estudos de Maria da Glória Gohn a qual foi de necessidade substancial para as questões que envolvem o caráter educativo dos movimentos sociais e que nortearam e constituíram objetivamente o enredo do audiovisual. Sendo assim, é plausível salientar que quando se fala de movimentos sociais, e que quando esses denotam a participação de grupos sociais relacionados à área educacional vale destacar que:

Falar da existência de um processo educativo no interior de processos que se desenvolvem fora dos canais institucionais escolares implica em ter, como pressuposto básico, uma concepção de educação que não se restringe ao aprendizado 
de conteúdos específicos transmitidos através de técnicas e instrumentos do processo pedagógico (GOHN, 1992, p. 17).

Sendo assim, Gohn nos esclarece que a construção do caráter educativo para além dos espaços institucionais abarcam tanto a dimensão da organização política a qual pretende-se reivindicar quanto a dimensão da cultura política. No que confere a dimensão da organização política, paulatinamente e progressivamente a consciência adquirida em relação aos direitos e deveres dos cidadãos na sociedade são as formas que legitimam um discurso e com ele a luta por demandas, no entanto, “este processo não se dá espontaneamente e dele participam vários agentes. As acessórias técnicas, políticas e religiosas que atuam junto aos grupos populares desempenham um papel fundamental no processo" (GOHN, 1992, p. 17). Logo ao identificar o grupo de interesses opostos e para que a construção da cidadania coletiva desempenhe um caráter educativo, é preciso que se criem estratégias de formulação das demandas e com elas táticas de enfrentamento dos grupos opostos.

Referente à dimensão da cultura política, a qual que para isso exerça de fato a função de vivência política, é inerente ao processo da práxis cotidiana. Essa práxis ao ser incorporada nos movimentos sociais adquire-se elementos de experiências do passado e do presente. Ao adquirir essa experiência, cumpre a possibilidade ou ao menos se espera, para a construção do futuro do exercício de se criar estratégias, pois segundo Gohn (1992, p. 19) "isso tudo porque ocorre a identificação do processo de ocultamento das diferenças sociais existentes e, consequentemente, a identificação dos distintos interesses de classe presentes". Logo, a importância e o reconhecimentos das causas e experiências de lutas e ocultamentos anteriores para se compreender o presente e que possa adquirir um sentido, por meio desse processo, um caráter educativo nos movimentos sociais para melhorias no futuro.

\section{OS MOVIMENTOS SOCIAIS NA CONSTRUÇÃO DO CURTA-METRAGEM}

Perante o exposto, vale enfatizar uma das premissas que nos guiou na idealização e construção do audiovisual foi diretamente influenciada pelo início do texto do Hagemeyer, onde ele aponta que

a história é fundamental para a construção de uma identidade (seja ela qual for), pois é a partir dela que refletimos sobre nossa existência no mundo comparando as situações e os desafios atuais com os de outras épocas e lugares (HAGEMAYER, 2012, p. 107).

Esse foi um dos primeiros textos a ser trabalhado por nós bolsistas no PIBID, antes mesmo de termos de fato o primeiro contato com as alunas/os na escola. Essa noção básica de 
história, identidade e empoderamento, nos nortearam sobre o que de fato nós queríamos trabalhar no nosso curta-metragem. A temática, sobre movimentos sociais veio depois, mas vontade de empoderar as ações coletivas de alunas (os) e professoras (es) no Colegião, já existia.

O colégio Eng $^{\circ}$ Sebastião Toledo dos Santos foi inaugurado em março de 1974, e como tal imerso numa atmosfera política, econômica e social, autoritária e repressora, perpassada pelo regime militar então vigente na época, 40 anos se passaram e chegamos em 2015, com o retorno as atividades na escola voltando ao normal depois de uma paralisação coletiva dos professores (as) que durou 72 dias. Nossa investigação nos guiou nesses 40 anos de existência do Colegião, por uma série de conflitos do movimento estudantil e de professores, com demandas específicas de cada período histórico, e com ações realizadas pelo coletivo de alunas (os) e professoras (es), que se organizaram, identificaram suas carências, politizaram suas demandas e partiram para ações coletivas, de enfrentamento, greves, ocupações e paralisações.

Mas antes de aprofundar e discutir algumas dessas ações e reivindicações, ressaltamos que nos ancoramos no conceito trabalhado pela Gohn, do que é movimento social, em 500 anos de lutas sociais no Brasil movimentos sociais, ONGs e terceiro setor Movimentos sociais são ações coletivas de caráter sociopolítico, construídas por atores sociais pertencentes a diferentes classes e camadas sociais. Eles politizam suas demandas e criam um campo político de força social na sociedade civil. Suas ações estruturam-se a partir de repertórios criados sobre temas e problemas em situações de conflitos, litígios e disputas. As ações desenvolvem um processo social e politico-cultural que cria uma identidade coletiva ao movimento, a partir de interesses em comum. Esta identidade decorre da força do principio da solidariedade e é construída a partir da base referencial de valores culturais e políticos compartilhados pelo grupo (GONH, 2000, p.13).

Pensando nisso, começamos nosso trabalho de investigação com uma análise acurada do acervo da escola, com o auxilio das alunas e alunos do magistério. Fotos, recortes de jornais, e entre outros documentos formavam um quadro fragmentado, que foi complementado com fontes do arquivo municipal, e outros suportes de informação como entrevistas, reportagens de telejornais, vídeos das manifestações.

O próprio momento político que alunas (os) e trabalhadores da educação de todo estado de Santa Catarina vivia então, com ações do Estado se organizando num sentido de 
desmonte e sucateamento do ensino público, com professores e professoras resistindo por meio de greves e reinvindicações foram válvula impulsora. Nos ajudaram a pensar num tema para o audiovisual voltado para os movimentos sociais, no espaço do Colegião. O que esperávamos de inicio com o projeto era “... equacionar as variáveis da condição humana e oferecer uma explicação original de um aspecto marginal da sociedade a partir dos seus fragmentos" (HAGEMEYER, 2012, p. 217). E entender como essas lutas extrapolaram o in sala, e provocaram mudanças efetivas, conquista do transporte público gratuito, derrubaram projeto de "reenturmação" que iriam superlotar as salas de aulas, e entre outras causas que deram visibilidade e legitimidade para o movimento estudantil e de professores.

No audiovisual foram abordados os movimentos estudantis e de professores, que foram surgindo nas fontes pesquisadas, optamos por nos restringir a três, por questões metodológicas e de recorte temporal. Discutimos o movimento do passe-livre de 2006 cujos alunos e alunas do Colegião foram protagonistas, a reenturmação de 2012 e por fim a participação do STS no movimento dos professores em 2015 contra a destruição do plano de carreira, e consequentemente a precarização e o desmonte da educação perpetrado pelo governo do estado de SC.

Em 2006, lideranças estudantis do Colegião, protagonizaram uma das maiores manifestações de estudantes em Criciúma nos últimos anos. Com o perigo eminente da prefeitura retirar os passes-livre de estudantes de escolas públicas, alunas e alunos foram as ruas, mobilizados, em paralizações, catracaços que pararam criciúma. A demanda, mais do que a carência do transporte público urbano, dizia a respeito a defesa de direitos já assegurados que estavam em risco. Assembleias, e coletivos foram organizados com colégios públicos de Criciúma e o governo teve que retroceder.

O sucateamento do ensino público se percebe claramente com fechamento de escolas, infraestrutura ineficiente, e o Estado resolveu em 2012 aliar esses problemas, ao chamado projeto de "reenturmação" onde com a medida para economizar na contratação de professores, turmas iam ser reorganizadas, superlotando as salas de aulas. A reação no Colegião foi imediata e passeatas foram organizadas juntamente com outros colégios da zona central e periférica de Criciúma.

Hoje os problemas continuam se amontoando, com o ano passado o ensino público de Criciúma parado com a greve de 72 dos professores, que lutavam contra a destruição dos seus planos de carreira pelo governo do estado. 
Dar subsídios para nossas alunas e alunos, encorpando sua prática com teoria, empoderando suas ações, proporcionando condições, caminhos para a liberação dos mesmos, como bem observado pelo Freire na Pedagogia do Oprimido, "ele (aluno) não é coisa que se resgata, é sujeito que se deve autoconfîgurar responsavelmente" (FREIRE, 1987).

\section{METODOLOGIA CONSTRUTIVA: O AUDIOVISUAL E SEUS DESDOBRAMENTOS}

O desenvolvimento do subprojeto Pibid de história utilizou-se de embasamento teórico a fim de possibilitar uma compreensão pertinente à temática desenvolvida. No decorrer do projeto foi exibidos recortes do filme "A guerra do fogo" de 1981, feito na França e no Canadá, com a direção de Jean Jacques Annaud. Anthony Burgess e Desmand Morris, a qual conta a história de um período anterior ao uso da escrita. Além disso, foi disponibilizado um roteiro para aprofundar as reflexões acerca da temática, no sentido de abarcar não só o desempenho do aluno e da turma, mas também a sequência de trabalho proposto, no andamento do programa.

Em seguida, foi proposta uma roda de debates com o objetivo de instrumentalizar os alunos sobre a noção básica de utilizar o audiovisual como suporte didático, fonte ou objeto de pesquisa, desenvolvendo um paralelo entre a veracidade do registro e o poder evocativo das simulações audiovisual e a história. De modo que ela possa levar o aluno, o professor ou o historiador a refletir; Quando? Onde? Quem? Para quem? Para quê? Por quê? Como? Olhando para o contexto em que foi feita, indagando a questão do ponto de vista do diretor, levar questões de nosso tempo para a época em que a representação foi criada, e evitar o anacronismo, que é o maior erro que um historiador pode cometer. E não sendo o retrato de uma verdade, nem a representação fiel de eventos ou objetos, deve ser visto como uma ponte de referências para questões acerca do conhecimento histórico. Sendo assim, trouxemos para a sala de aula outra possibilidade de se trabalhar a história, a qual deixa de ser uma única verdade e passando a ser refletida, questionada e analisada.

Após estes questionamentos, partimos para a segunda etapa da qual foi realizada uma oficina de documentação, cuja atividade enfatizou a importância da preservação da memória e documentação. Nesse momento da oficina de documentação, foi feito primeiramente uma instrumentalização da relevância com os bolsistas pibidianos no setor de Restauro da universidade. Para em seguida, aplicar com os alunos na escola, onde foi possível com o apoio do setor de Restauro da Unesc, com materiais para a confecção das cadernetas. Neste 
viés, foram repassadas informações sobre a higienização e preservação de documentos antigos. A caderneta foi elaborada da seguinte forma: costura em três pontos, a qual continha informações importantes sobre a preservação de um documento em suporte de papel. Portanto, propiciar aos alunos uma nova percepção sobre preservação e a importância do documento proporcionando ao mesmo este contato de cuidar e armazenar de maneira correta, para que não se percam e a partir desta conscientização de que o documento também é história e que o mesmo é objeto de construção para realizações de audiovisuais na história.

Assim, a turma foi orientada a iniciar a pesquisa no Arquivo Público Municipal de Criciúma e ao Arquivo particular da Escola Sebastião Toledo dos Santos (Colegião), para a construção do suporte documental do curta-metragem. Em seguida, foram coletadas depoimentos de ex-alunos e do movimento dos professores de diversas épocas mediados pelos alunos e registrado na forma de MP3. Esse momento foi único e repleto de reflexões, pois a construção do curta-metragem girou em torno das questões sobre o movimento estudantil, porém com a visão dos próprios alunos na construção do curta, isto é, os mesmos se viam e participavam na elaboração fílmica, estabelecendo aí, um conhecer e um produzir em torno da temática pré-estabelecida e sendo identificadas e compreendidas diante do conhecimento de que esses alunos também são parte da história.

Contudo, é importante salientarmos que o momento de socialização durante todo o processo e desdobramento do projeto na construção do audiovisual foi de suma importância, possibilitando um intrínseco saber acerca do suporte documental. O eixo central da proposta girou em torno da instrumentalização dos alunos, da importância da conservação e preservação de documentos, como forma de suporte de informação na construção da história e base fundamental para realização do audiovisual contando a participação da escola Engo . Sebastião Toledo Santos no movimento estudantil e dos professores.

Discutir a organização e a luta de professores (as) e alunas (os) em três períodos diferentes, para a turma do magistério com quem trabalhamos, não só proporcionou um contato com um outro material didático, que posteriormente poderia ser usado por eles mesmo em sala de aula. Como possibilitou um contato direto com a história da escola, que nada mais é que a historia dos próprios alunos (as), era essa a história que nos interessava desde o inicio. Discutir política, dentro de sala de aula, de acadêmicos que serão professores, para alunas (os) do magistério que também serão, é uma experiência incrível, de possibilitar acesso de ambos 
a outras linguagens, mais principalmente de expandir a nossa capacidade como acadêmica (o) e docente de aprender com o outro.

A ideia de dar espaço no audiovisual, para a voz de estudantes e professores fossem ouvidas, demandas e ações reconhecidas e de certa forma eternizadas num curta-metragem pensado e produzido por alunas e alunos que também ocupam esse espaço pedagógico, e que também o oxigenam cotidianamente com ideias, sonhos, valores e ações. É o grande mérito desse projeto, de instrumentalizar agentes transgressores dentro da escola, que brevemente vão ser educadores. Perceber que os movimentos sociais nada mais são do que a ação dos homens e mulheres na história, e envolve intrinsecamente um fazer, um se organizar, solidariedade e uma eterna luta de classes, que nunca esteve tão viva.

\section{REFERÊNCIAS}

BITTENCOURT, C. M. F. Usos didáticos de documentos. In: BITTENCOURT, C. M. F. Ensino de História: fundamentos e métodos. São Paulo: Cortez, 2004, p. 327-350.

BRODBECK, M. S. L. Vivenciando a História: Metodologia de Ensino da História. Curitiba: Base Editorial, 2012.

FREIRE, P. Pedagogia do Oprimido. Rio de Janeiro: Paz e Terra, 1987.

GOHN, M. G. M. Movimentos sociais e educação. São Paulo: Ed. Cortez, 1992. 117 p.

GOHN, M. G. M. Movimentos sociais e redes de mobilizações civis no Brasil contemporâneo. 7 ed. Petrópolis: Vozes, 2013.

GOHN, M. G. M. 500 anos de lutas sociais no Brasil movimentos sociais, ONGs e terceiro setor. Revista Mediações, Londrina, v. 5, n. 1, p. 11-40, jan/jun 2000.

HAGEMEYER, R. R. A história nos meios audiovisuais: entre a veracidade do registro e o poder evocativo das simulações. In: HAGEMEYER, R. R. História \& Audiovisual. Belo Horizonte: Autêntica Editora, 2012, p. 107-151.

LE GOFF, J. História e memória. 5 ed. Campinas, SP: UNICAMP, 2003.

SAMARA, E. M.; TUPY, I. S. S. T. O trabalho com o documento. In: SAMARA, E. M.; TUPY, I. S. S. T. História \& documento e metodologia de pesquisa. 2 ed. Belo Horizonte: Autentica Editora, 2010, p. 67-116.

VALIM, A. História e cinema. In: CARDOSO, C. F.; VAINFAS, R. Novos domínios da História. Rio de Janeiro: Elsevier, 2012. 